\title{
HLA class II gene frequencies in Crohn's disease: a population based analysis in Germany
}

\author{
M Reinshagen, C Loeliger, P Kuehnl, U Weiss, B J Manfras, G Adler, B O Boehm
}

\begin{abstract}
Background-Ulcerative colitis is the only known inflammatory bowel disease associated with particular HLA alleles. Whereas the association with the HLADRB1*15 allele has been described in several independent studies for ulcerative colitis, no contribution of HLA alleles to susceptibility in Crohn's disease has yet been shown.

Aim-This study was designed to study the strength of association of HLA class II alleles as risk markers for Crohn's disease in a homogenous population in Germany. Patients-A total of 4251 randomly selected control subjects, and 162 unrelated subjects with Crohn's disease were studied. Subjects were studied for their HLA-DRB1, HLA-DQA1, and HLADQB1 alleles.
\end{abstract}

Method-HLA DNA typing was performed after locus specific amplification with the polymerase chain reaction and reverse dot blot hybridisation.

Results-The HLA-DRB1*07 was the only HLA class II allele found to be significantly associated with Crohn's disease (relative risk $(R R)=1.9,95 \%$ CI: 1.66 to $2 \cdot 14 ; p=0.0001$ ). This association remained significant after correction for the number of DRB1 alleles compared. In patients with disease onset before 35 years the $R R$ for the disease in HLA-DRB1*07 positive subjects was found to be higher $(\mathbf{R R}=3 \cdot 1,95 \%$ CI: $2 \cdot 44$ to 3.76). The HLADRB1*03 was significantly decreased in frequency in Crohn's disease $(R R=0.5$, 95\% CI: 0.39 to $0.61 ; p=0.0028$ ).

Conclusion-The HLA-DRB1*07 allele provides risk for the disease especially in patients with younger ages of onset. These data also provide indirect evidence for an immunogenetically based heterogeneity of the disease.

(Gut 1996; 38: 538-542)

Keywords: Crohn's disease, disease heterogeneity, HLA, polymerase chain reaction.

Family and twin studies have provided evidence for a genetic susceptibility to inflammatory bowel disease (for a detailed review see ref 1 ). The most strongly associated genetic markers for inflammatory bowel disease thus far are provided by the polymorphic cell surface molecules of the major histocompatibility complex - that is, the HLA class I, and the HLA class II gene products.

Presence of the HLA-B27 specificity in inflammatory bowel disease patients with simultaneous presence of ankylosing spondylitis was reported. ${ }^{12}$ Furthermore an association of ulcerative colitis with primary sclerosing cholangitis and the serologically defined specificities HLA-B8 and HLA-DR3 has been found. ${ }^{1}$ In addition, other HLA class I and class II specificities have been described to be associated with the disease. ${ }^{34}$ All these studies were carried out with classic serological HLA typing techniques and have provided inconclusive results. ${ }^{14}$ Only a few studies have considered the role of HLA genes as markers for inflammatory bowel disease with novel DNA typing procedures. In a recent study, white subjects from the United States were HLA genotyped. In this study an association of ulcerative colitis with HLA-DR2 (DRB1*15 is a split of the DR2 specificity) has been reported. ${ }^{5}$ Furthermore, the HLA-DQw5 specificity, which was provided by a HLADR1-DQw5 positive HLA-haplotype, contributed to Crohn's disease susceptibility in that study. ${ }^{5}$

While the association of HLA genes with ulcerative colitis seems now well established, the association of the serological defined HLADR locus with Crohn's disease is much more controversial. The combined analysis of three earlier studies in white populations showed no association of the serologically defined HLA-DR alleles with Crohn's disease. ${ }^{6-8}$ No evidence for an association of HLA-DR antigens and Crohn's disease was provided in a segregation analysis of HLA haplotypes in multiplex Crohn's disease families, as no significant deviation from Mendelian segregation was seen..$^{10}$

In our study we have compared HLA DNA typing results from 162 patients with Crohn's disease to the HLA typings taken from 4251 healthy local controls. All subjects studied were white of German origin from the same local area. We sought to discover if class II genes represent risk markers for the disease. As HLA class II antigens are well known for their important role as immune response genes, we also intended to define structural features of the class II genes with respect to disease susceptibility and protection for Crohn's disease.

\section{Methods}

Patients and controls

A total of 4251 unrelated control subjects (2268 men, 1983 women) were recruited from the same local area and were of the same ethnic origin (white subjects). The mean age was $35 \cdot 2$ (range 18 to 58 years). These control subjects
Professor B O Boehm Department of Medicine I, University of Ulm, RobertKoch-Strasse 8, 89070

Accepted for publication 9 October 1995 


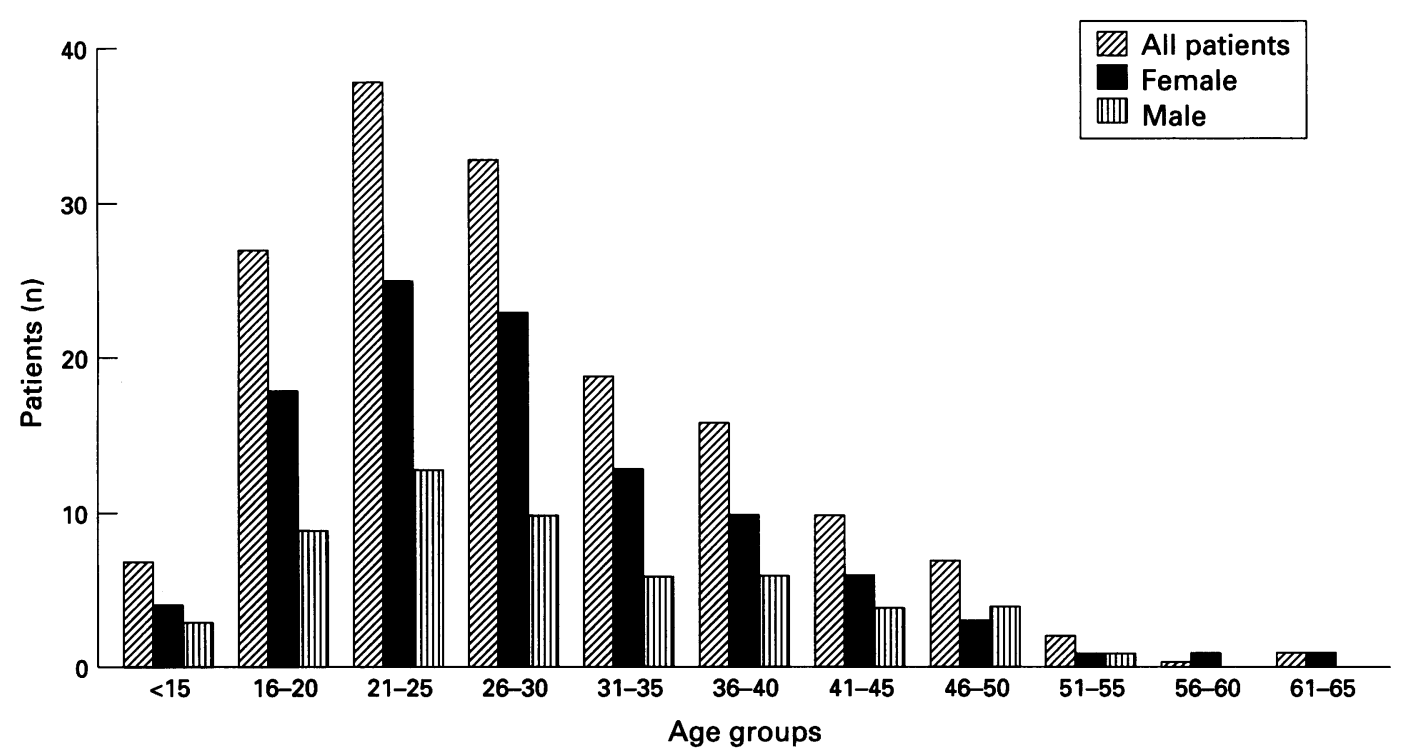

Figure 1: Ages at manifestation of the disease.

were healthy blood donors and healthy volunteers for bone marrow donation. The cohort of unrelated patients with Crohn's disease ( $n=162 ; 106$ women, 56 men) included 1272 patient years. The average duration of the disease was 7.8 years (range 1-27 years). The mean age of the patients was 35.6 (range 9-65 years). The diagnosis of Crohn's disease and the disease localisation was confirmed in all patients by standard diagnostic procedures, which included endoscopy, histology, and radiological small bowel studies. Figure 1 summarises the ages as the start of the disease. The distribution of the disease localisation was: 88 of 162 (54\%; 54 women, 34 men) patients had an inflammation of the ileum, whereas 74 (46\%; 49 women, 25 men) had an inflammatory process also of the large bowel. From the 74 patients with a disease localisation in the colon 31 patients had Crohn's colitis, whereas in 43 patients active disease was found in the ileum and the colon.

Genomic HLA class II genotyping

The HLA-DRB1, -DQA1, and -DQB1 alleles were determined by use of a locus specific amplification procedure as described elsewhere. ${ }^{11}$ In brief, $1 \mu \mathrm{g}$ of genomic DNA, which had been extracted from peripheral blood leucocytes, was added to $10 \mu \mathrm{l}$ of prepacked biotinylated primer mixes each of which corresponded to a given HLA class II locus, for example, HLA-DRB1, HLA-DQA1, and HLA-DQB1, respectively. After 35 cycles of polymerase chain reaction (PCR) amplification in an automatic thermocycler (Thermocycler 9600, Perkin Elmer Cetus) the amplificate was denatured by sodium hydroxide and hybridised to sequence specific oligonucleotides, which were fixed after oligo-dT tailing to a nylon membrane (Hybond N, Biodyne B, Pall Filtration Ltd, Portsmouth, UK). Allele specific hybridisation of the locus specific amplificate was detected by adding streptavidine coupled peroxidase and a colourimetric reaction of tetra-methyl-bencidine. As a control of the reverse dot blot protocol the standard DNA typing procedure of the 11 th International HLA Workshop was used in randomly collected samples. ${ }^{1213}$ One hundred and forty eight subjects were typed with both methods. One hundred per cent congruence of the typing results could be shown. In all typing procedures, DNA from homozygous typing cell lines (10th International HLA Workshop panel: number of HTCs included: $n=27$ ) were also included as internal controls. Our laboratory took part in the recent 11 th International HLA Workshop and in the ongoing 12th International HLA Workshop; the workshop identification numbers are GER/BOE 332 and GER/KUE 338.

The following HLA-DRB1 alleles could be determined with the HLA genotyping procedures: HLA-DRB $1{ }^{\star} 01,{ }^{\star} 15,{ }^{\star} 16,{ }^{\star} 03$, $\star_{04},{ }^{\star} 11,{ }^{\star} 12,{ }^{\star} 13,{ }^{\star} 14,{ }^{\star} 07,{ }^{\star} 08,{ }^{\star} 09$, and ${ }^{\star} 10$ (13 alleles). Very rare HLA-DRB1 alleles or splits have not been considered. The following HLA-DQA1 alleles were determined: HLADQA $1{ }^{\star} 0101-{ }^{\star} 0103,{ }^{\star} 0201,{ }^{\star} 0301,{ }^{\star} 0401$, and $\star 0501$ ( $n=7$ alleles). The following HLADQB1 alleles were determined: HLADQB1 ${ }^{\star} 0501$ to ${ }^{\star} 0503,{ }^{\star} 0601$ to ${ }^{\star} 0605,0201$, ${ }^{\star} 0301-{ }^{\star} 0303$, and ${ }^{\star} 04$ (13 alleles).

Amino acid comparison of class II antigens

Published sequences of HLA class II antigens were analysed. The amino acid sequences were taken from a computer based source kindly provided by $\mathrm{S}$ Marsh, Tissue Antigen Laboratory, Imperial Cancer Research Fund, London ('HLA class II region nucleotide sequences', Version October 1994).

\section{Statistical analysis}

The $\chi^{2}$ test was used as described. ${ }^{14}$ Relative risk (RR) was calculated using Woolf's formula, the aetiological fraction, and the preventive fraction, which provide an estimate of the relative contribution of a marker to the 
TABLE I HLA-DRB1 gene frequencies in patients with Crohn's disease and local controls

\begin{tabular}{|c|c|c|c|c|c|c|c|}
\hline & \multicolumn{2}{|c|}{$\begin{array}{l}\text { Crohn's disease } \\
a=320\end{array}$} & \multicolumn{2}{|c|}{$\begin{array}{l}\text { Controls } \\
a=8502\end{array}$} & \multirow[b]{2}{*}{$R R$} & \multirow[b]{2}{*}{$x^{2}$} & \multirow{2}{*}{$\stackrel{p}{\text { Value }}$} \\
\hline & $a$ & $g f(\%)$ & $a$ & $g f(\%)$ & & & \\
\hline \multicolumn{8}{|c|}{ DRB1-allele } \\
\hline$\star 01$ & 27 & $8 \cdot 4$ & 920 & $10 \cdot 8$ & & & \\
\hline$\star 15$ & 43 & $13 \cdot 4$ & 1040 & $12 \cdot 2$ & & & \\
\hline$\star 16$ & 4 & $1 \cdot 3$ & 136 & $1 . \overline{6}$ & & & \\
\hline$\star 03$ & 21 & $6 \cdot 6$ & 1020 & 11.9 & $0.5(0.39$ to 0.61$)$ & 8.9 & $0 \cdot 0028$ \\
\hline${ }^{\star} 04$ & 42 & $15 \cdot 0$ & 1463 & $17 \cdot 1$ & & & \\
\hline$\star 11$ & 36 & $11 \cdot 3$ & 1048 & $12 \cdot 3$ & & & \\
\hline$\star 12$ & 5 & 1.6 & 126 & 1.5 & & & \\
\hline$\star 13$ & 50 & $15 \cdot 6$ & 1202 & $14 \cdot 1$ & & & \\
\hline$\star 14$ & 8 & $2 \cdot 5$ & 289 & $3 \cdot 4$ & & & \\
\hline$\star 07$ & 59 & $18 \cdot 4$ & 886 & $10 \cdot 4$ & $1.9(1.66$ to 2.14$)$ & $20 \cdot 7$ & 0.0001 \\
\hline$\star 08$ & 13 & $4 \cdot 1$ & 289 & $3 \cdot 3$ & & & \\
\hline$\star 09$ & 1 & 0.3 & 50 & 0.6 & & & \\
\hline$\star 10$ & 5 & $1 \cdot 6$ & 33 & $0 \cdot 4$ & & & \\
\hline Total & 320 & & 8502 & & & & \\
\hline
\end{tabular}

$a=$ number of alleles; $g f=$ gene frequency; $R R=$ relative risk; $95 \%$ confidence intervals are given in brackets. The threshold for significance of a deviation was given by a corrected $p$ value of $\leqslant 0 \cdot 0038$

disease, were calculated as described. ${ }^{15-17}$ The Bonferoni inequality method was used to correct for each antigen comparison. ${ }^{18}$ The threshold for significance of a deviation for the HLA-DRB 1 and HLA-DQB1 alleles was given by a corrected $p$ value of $\leqslant 0 \cdot 0038$, and for the HLA-DQA1 alleles by a corrected $p$ value of $\leqslant 0.0071$.

\section{Results}

\section{HLA-DRB1 alleles}

Table 1 shows the gene frequencies in patients with Crohn's disease. A total of 320 alleles from Crohn's patients and 8502 alleles from control subjects have been compared. HLA-DRB $1{ }^{\star} 03$ was found to be significantly decreased in frequency in Crohn's disease patients when compared with the controls (gene frequency: $6.6 \%$ versus $11.9 \% ; p=0.0028)$. A RR of $1.9(95 \%$ CI: 1.66 to $2 \cdot 14 ; p=0.0001$ ) was found for the presence of HLA-DRB1*07 (gene frequency: $18.4 \%$ in Crohn's disease versus $10.4 \%$ in controls). This association remained significant after correction for the number of DRB1-alleles compared. The aetiological fraction of the DRB $1^{\star} 07$ allele could be calculated as $9 \%$. The reduction of both, the HLA-DRB $1^{\star} 01$ and the $\mathrm{DRB} 1^{\star} 04$ allele, did not reach a level of significance. There were six HLA-DRB ${ }^{\star} 07$ homozygous patients. On the basis of a gene frequency of 0.184 the expected number of homozygous patients was $5 \cdot 4$.

TABLE II HLA-DQA1 gene frequencies in patients with Crohn's disease and local controls

\begin{tabular}{|c|c|c|c|c|c|c|c|}
\hline & \multicolumn{2}{|c|}{$\begin{array}{l}\text { Crohn's disease } \\
a=320\end{array}$} & \multicolumn{2}{|c|}{$\begin{array}{l}\text { Controls } \\
a=4882\end{array}$} & \multirow[b]{2}{*}{$R R$} & \multirow[b]{2}{*}{$x^{2}$} & \multirow{2}{*}{$\stackrel{p}{\text { Value }}$} \\
\hline & $a$ & $g f(\%)$ & $a$ & $g f(\%)$ & & & \\
\hline $\begin{array}{l}\text { DQA1 } \\
\star 00101 \\
\star_{0} 0102 \\
\star_{0} 0103 \\
{ }^{\star} 0201 \\
{ }^{*} 0301 \\
{ }^{\star} 0401 \\
{ }^{\star} 0501\end{array}$ & $\begin{array}{r}\text { lele } \\
39 \\
68 \\
20 \\
60 \\
49 \\
13 \\
67\end{array}$ & $\begin{array}{r}12 \cdot 3 \\
20 \cdot 1 \\
6 \cdot 3 \\
18 \cdot 9 \\
15 \cdot 5 \\
4 \cdot 1 \\
21 \cdot 2\end{array}$ & $\begin{array}{r}721 \\
1025 \\
449 \\
540 \\
738 \\
145 \\
1264\end{array}$ & $\begin{array}{r}14 \cdot 8 \\
20 \cdot 9 \\
9 \cdot 2 \\
11 \cdot 1 \\
15 \cdot 1 \\
2 \cdot 9 \\
25 \cdot 9\end{array}$ & $0.8(0.59$ to 1.0$)$ & $14 \cdot 8$ & 0.0321 \\
\hline Total & 320 & & 4882 & & & & \\
\hline
\end{tabular}

The $95 \%$ confidence intervals are given in brackets. The threshold for significance of a deviation was given by a corrected $\mathrm{p}$ value of $\leqslant 0.0071$. Abbreviations as Table I.

\section{$H L A-D Q A 1$ alleles}

Table II summarises the HLA-DQA1 typing results. A total of 320 alleles from Crohn's patients and 4882 alleles from the controls could be compared. No difference could be seen for the HLA-DQA1 alleles ${ }^{\star} 0101,{ }^{\star} 0102$, and $\star 0103$ when compared with the controls. A RR of 1.9 was calculated, for the presence of the HLA-DQA1 ${ }^{\star} 0201$ allele $(p=0.0001)$. The correct $p$ values also showed a significant deviation of the corresponding genotype. The HLA-DQA ${ }^{\star} 0501$ allele was found to be reduced in its frequency (gene frequency: $21.1 \%$ versus $25.9 \% ; p=0.0321$ ), but this difference did not reach significance.

\section{$H L A-D Q B 1$ alleles}

Table III summarises the HLA-DQB1 typing in Crohn's patients and controls. A total of 320 alleles in Crohn's patients and 1456 alleles in controls were compared. A slight increase of the DQB $1{ }^{\star} 0501$ allele was seen in the control subjects compared with Crohn's disease patients (11\% versus $9.7 \%$ ). Also a slight increase of the $\star 0602$ allele was found in control $(11.6 \%$ versus $13 \cdot 1 \%$ ), whereas the HLA-DQB $1^{\star} 0302$ allele was found to be decreased $(9.6 \%$ versus $11.9 \%)$. These differences were not statistically significant.

Heterogeneity of Crohn's disease population:

$H L A$ and age of onset of the disease

The cohort of patients with Crohn's disease was large enough to be subdivided according to the age of onset of the disease (see also Fig 1). The genotype frequency of the disease associated $\mathrm{DRB} 1^{\star} 07$ allele differed considerably in the cohort of patients with onset of the disease before 35 years versus an older age of onset. The frequencies were $26 \cdot 5 \%$ versus $14 \cdot 1 \%$ $\left(x^{2}=4 \cdot 2\right)$. The RR for the disease in patients with the HLA-DRB $1^{\star} 07$ allele was also different when calculated for the two subgroups of patients (a) $<35$ years of age $R R=3 \cdot 1(95 \% \mathrm{CI}$ : 2.44 to $\left.3.76 ; \chi^{2}=52.5 ; p=0.0001\right)$, (b) $\geqslant 35$ years of age $R R=1.4$ (not significant). Furthermore, all six $\mathrm{DRB} 1^{\star} 07$ homozygous patients had an age of onset before age 30 .

HLA association with clinical subsets: localisation of the inflammatory process

The cohort of patients with Crohn's disease could be subdivided into two subgroups - that is, with $(n=74)$ and without $(n=88)$ inflammation of the large bowel. No differences in both groups could be found for the prevalences of the disease associated HLA-DRB $1^{\star} 07$ allele or the so called preventive HLA-DRB ${ }^{\star} 03$ allele. We also considered whether an inflammation in the colon in Crohn's disease patients could be attributed to the presence of the HLA$\mathrm{DRB}^{\star}{ }^{\star} 15$ allele. This allele also provides a strong risk for ulcerative colitis in our study population (data not shown). The genotype frequency of DRB1* 15 allele was found not to be different between the subgroups with and without inflammation of the large bowel. 
TABLE III $H L A-D O B 1$ gene frequencies in patients with Crohn's disease and local controls

\begin{tabular}{|c|c|c|c|c|c|c|}
\hline & \multicolumn{2}{|c|}{$\begin{array}{l}\text { Crohn's disease } \\
a=320\end{array}$} & \multicolumn{2}{|c|}{$\begin{array}{l}\text { Controls } \\
a=1.456\end{array}$} & \multirow[b]{2}{*}{$R R$} & \multirow[b]{2}{*}{$x^{2}$} \\
\hline & $a$ & $g f(\%)$ & $a$ & $g f(\%)$ & & \\
\hline \multicolumn{7}{|c|}{ DQB1-allele } \\
\hline$\star 0501$ & 31 & $9 \cdot 7$ & 151 & $11 \cdot 0$ & & \\
\hline *0502 & 5 & $1 \cdot 6$ & 44 & $3 \cdot 0$ & & \\
\hline$\star 0503$ & 13 & $4 \cdot 0$ & 39 & $2 \cdot 7$ & & \\
\hline${ }^{\star} 0601$ & 1 & $0 \cdot 3$ & 8 & 0.5 & & \\
\hline$\star 0602$ & 37 & $11 \cdot 6$ & 191 & $13 \cdot 1$ & & \\
\hline${ }^{\star} 0603$ & 16 & $5 \cdot 0$ & 111 & $7 \cdot 6$ & & \\
\hline$\star_{0604}$ & 20 & $6 \cdot 2$ & 66 & $4 \cdot 5$ & & \\
\hline$\star 0605$ & 0 & 0 & 5 & 0.3 & & \\
\hline${ }^{\star} 0201$ & 58 & $18 \cdot 1$ & 282 & $19 \cdot 4$ & & \\
\hline$\star 0301$ & 67 & 20.9 & 298 & 20.5 & & \\
\hline$\star 0302$ & 38 & 11.9 & 140 & $9 \cdot 6$ & & \\
\hline$\star 0303$ & 16 & $5 \cdot 0$ & 82 & $5 \cdot 6$ & & \\
\hline${ }^{\star} 04$ & 18 & $5 \cdot 6$ & 36 & $2 \cdot 5$ & & \\
\hline Total & 320 & & 1456 & & & \\
\hline
\end{tabular}

The threshold for significance of a deviation was given by a corrected $p$ value of $\leqslant 0.0038$. Abbreviations as Table I.

Sequence comparison between disease associated and protective $H L A-D R B 1$ alleles

The comparison between HLA-DRB1*01 (used as consensus sequence), DRB1*15 (associated with ulcerative colitis), and DRB1*07 (associated with Crohn's disease) and the 'protective' DRB $1{ }^{\star} 03$ allele showed several 'critical' positions (see Fig 2). At amino acid position 9, the hydrophobic non-polar amino acid tryptophane was found in all inflammatory bowel disease associated $\beta$ chain molecules, whereas the $\mathrm{DRB}{ }^{\star} 0301$ molecule showed the acidic amino acid glutamic acid (Fig 2). At position 11, again a hydrophobic nonpolar amino acid was found (leucine), whereas $\mathrm{DRB} 1{ }^{\star} 03$ molecule showed an uncharged polar amino acid, glycine. Also at position 26 a hydrophobic non-polar amino acid could be found in inflammatory bowel disease associated DRB1 alleles (leucine and phenylalanine), whereas HLA-DRB1*03 showed the uncharged polar amino acid tyrosine. Finally, an important difference was seen at amino acid 32, where the aromatic amino acid tyrosine, which is present in ulcerative colitis and Crohn's disease associated HLA-alleles, is substituted with the basic amino acid histidine in the 'protective' HLA-DRB1 ${ }^{\star} 03$ molecule.

\section{Discussion}

Our population based study was able to define for the first time an association of a HLA class II allele with Crohn's disease. Our study did not have problems associated with ethnic diversity. We used a DNA based HLA typing procedure, which is highly reproducible for HLA class II typing. In our analysis a single HLA-DRB1 allele was found to be associated with Crohn's disease. This result confirmed an earlier report of our group in multiplex families. ${ }^{19}$ A cosegregation of a HLA-DRB7 positive haplotype with the disease had been found in familial Crohn's disease. A major contribution of HLA-DQ molecules for disease susceptibility could not be confirmed in Crohn's disease. The increase of the HLADQA ${ }^{\star} 0201$ allele was directly related to the higher prevalence of $\mathrm{DRB} 1^{\star} 07$-positive HLA haplotypes and can therefore be attributed to linkage disequilibrium.

Most DRB $1{ }^{\star} 07$ positive haplotypes showed the HLA-DQB1*0201 allele, which was also found on the 'protective' HLA-DRB1*03 positive HLA haplotype and may further substantiate our view that HLA-DQ molecules do not play a major part, at least as risk markers, for Crohn's disease.

HLA molecules function as peptide binding cell surface glycoproteins. The complex of peptide and HLA molecule is then presented to the $\mathrm{T}$ cell receptor. ${ }^{20}$ Therefore, histocompatibility proteins play a major part in the functioning of the immune system. The determination of the $x$ ray structure of a human class II molecule, and the characterisation of peptides bound to HLA class II molecules, ${ }^{21-23}$ provided a framework for the structural requirements of peptide binding to class II molecules. Provided that the HLA-DRB1*07 molecule is directly involved in peptide presentation to $\mathrm{T}$ cells in Crohn's disease, differences in the peptide binding requirements of disease associated versus protective HLA alleles can probably be detected. The question may arise as to whether the different amino acids of the various $\beta$ chain molecules exert any influence on the source of peptides bound to the groove of the class II molecules. ${ }^{22} 23$ An analysis of the relative frequency and source of peptides bound to six HLA-DR alleles, HLA-DR1, -DR2, -DR3, -DR4, -DR7, and -DR8 had shown important differences between the amount of bound peptides derived from exogenous serum proteins, endogenous membrane associated/ secretory proteins, and endogenous cytosolic proteins. ${ }^{22}$ The amount of exogenous peptides bound to the HLA-DR3 molecules (around $30 \%$ ) was several times larger compared with the HLA-DR1, HLA-DR2, and HLA-DR7 molecules ( 5 to $10 \%$ ) in that study. HLA-DR1 and HLA-DR2 molecules showed a fairly equal distribution pattern of peptides derived from all three sources studied. The amount of peptides coming from the cytosol was highest for the HLA-DR7 molecules and was the unique feature of this class II molecules compared with all other HLA class II molecules analysed thus far. These data may point to differences in the peptide binding and presentation of the various disease associated HLA-DRB1 alleles compared with the putatively protective DRB1

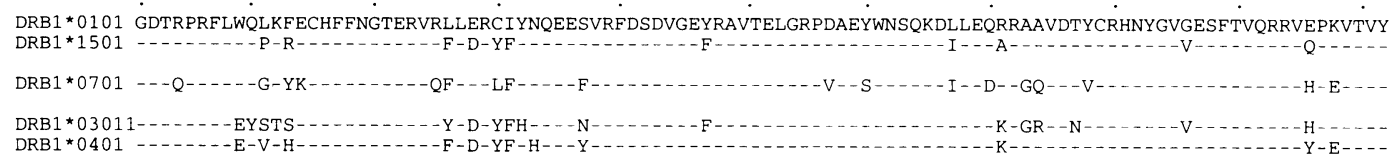

Figure 2: The amino acid positions of the $\beta$ chain molecule are given at the top of the Figure. Amino acids are given in one letter symbols. 
alleles with respect to Crohn's disease susceptibility.

Our study shows that class II alleles contribute only weakly to disease susceptibility as measured by the so called population attributable risk (aetiological fraction) or the preventive fraction. This can be explained by two alternative hypotheses. Ulcerative colitis and Crohn's disease may be heterogenous on clinical grounds. Indirect evidence for this is the different association of $\mathrm{DRB} 1^{\star} 07$ allele with age of onset. Inflammatory bowel disease may be comprised of several distinct subtypes, each of which having a distinct HLA association. An alternative hypothesis might be that the markers tested herein were not related to the disease or they may not be in strong linkage disequilibrium with other disease loci in the MHC gene region. To answer this question, several other markers from the HLA locus and other loci from the genome have to be considered.

Recently, it was suggested that superantigens, which do bind to class II alleles in a non-allele restricted manner may play a part in the cell mediated immune mechanisms of Crohn's disease (see review in ref 24). Superantigens as a trigger of autoimmunity within the gut may also provide an explanation for observed weak association of HLADRB1*07 with Crohn's disease.

This study was supported by grants from Deutsche Forschungsgemeinschaft (Bo 829/4-2, Bo 829/6-1; Rei 789/2-1).

1 McConnell RB, Vadheim CM. Inflammatory bowel disease. In: King RA, Rotter JI, Motulsky AG, eds. The genetic basis of common diseases. New York: Oxford University Press, 1992: 326-48.

2 Acheson ED. An association between ulcerative colitis, regional enteritis and ankylosing spondylitis. $Q \mathcal{f} \mathrm{Med}$ 1960; 29: 489-99.

3 Schrumpf E, Fausa O, Forre O, Doubloug JH, Ritland S, Thorsby E. HLA antigens and immunoregulatory T cells in ulcerative colitis associated with hepatobiliary disease. Scand $\mathcal{f}$ Gastroenterol 1982; 17: 187-91.

4 Tiwari JL, Terasaki PI. HLA and disease associations. New York: Springer-Verlag, 1985

5 Toyoda H, Wang SJ, Yang HY, Redford A, Magaloing D, Tyan D, et al. Distinct associations of HLA class II genes with inflammatory bowel disease. Gastroenterology 1993; 4: 741-8.

6 Pena AS, Biemond I, Kuiper G, Weterman IT, Van
Leeuwen A, Schreuder I. HLA antigen distribution and HLA haplotypes segregation in Crohn's disease. Tissue Antigens 1982; 16: 56-61.

7 Smolen JS, Gangl A, Polterauer P, Menzel EJ, Mayr WR. HLA antigens in inflammatory bowel disease. Gastroenterology 1982; 82: 34-8.

8 Caruso C, Olivia L, Palmeri P, Cottone M. B cell alloantigens in Sicilian patients with Crohn's disease. Tissue Antigens 1983; 21: 170-2.

9 Achord JL, Gunn CH, Jackson JF. Regional enteritis and HLA concordance in multiple siblings. Dig Dis Sci 1982; 27: 330-2.

10 Schwartz SE, Siegelbaum SP, Fazio TL, Hubbell C, Henry JB. Regional enteritis: evidence for genetic transmission by HLA typing. Ann Intern Med 1980; 93: 424-7.

11 Erlich $H$, Bugawan $T$, Begovich $A B$, Scharf $S$, Griffith $R$, Saiki R, et al. HLA-DR, DQ and DP typing using PCR amplification and immobilized probes. Eur $\mathcal{F}$ Immunogen 1991; 18: 33-5.

12 Kimura A, Sasazuki T. Eleventh International Histocompatibility Workshop reference protocol for HLA DNA-typing technique. In: Tsuji K, Aizawa M, Sasazuki $\mathrm{T}$, eds. HLA 1991, Proceedings of the 11th International Histocompatibility Workshop and Conference. Oxford: Oxford Science Publications, 1992: 397-419.

13 Kimura A, Dong RP, Harada H, Sasazuki T. DNA typing of HLA class II genes in B-lymphoblastoid cell lines homozygous for HLA. In: Tsuji K, Aizawa M, Sasazuki $\mathrm{T}$, eds. HLA 1991, Proceedings of the 11th International Histocompatibility Workshop and Conference. Oxford: Oxford Science Publications, 1992: 419-25.

14 Rose NR, Friedmann H, Fahey JL. Manual of clinical laboratory immunology. 4th ed. Washington DC: American ratory immunology. 4th ed. Wash

15 Woolf $\mathrm{B}$. On estimating the relation between blood group and disease. Ann Hum Genet 1956; 20: 309-11.

16 Green A. The epidemiologic approach to studies of association between HLA and disease. I The basic measures, concepts and estimation procedures. Tissue Antigens 1982; 19: 245-58.

17 Green A. The epidemiologic approach to studies of association between HLA and disease II. Estimation of absolute risks, etiologic and preventive fraction. Tissue Antigens 1982; 19: 259-68.

18 Dunn OJ. Multiple comparisons among means. Am $\mathcal{f}$ Stat Assoc 1961; 56: 52-64.

19 Kühnl P, Sibrowski W, Boehm BO, Bender W, Kalmar G, Löliger C. HLA antigen frequencies in familial Crohn's disease (CD). Beitr Infusionsther 1990; 26: 283-6.

20 Stern LJ, Wiley DC. Antigenic peptide binding by class I and class II histocompatibility proteins. Structure 1994; 2 : 245-51.

21 Rammensee HG, Friede T, Stevanovic S. MHC ligands and peptide motifs: first listing. Immunogenetics 1995; 41: 178-228.

22 Chicz RM, Urban RG, Gorga JC, Vignali AA, Lane WS, Strominger JL. Specificity and promiscuity among naturally processes peptides bound to HLA-DR alleles. $\mathcal{f} \operatorname{Exp}$ Med 1993; 178: 27-47.

23 Davenport MP, Quinn CL, Chicz RM, Green BN, Willis AC, Lane WS, et al. Naturally processed peptides from two disease-resistance-associated HLA-DR13 alleles show related sequence motifs and the effects of the dimerphism at position 86 of the HLA-DR $\beta$ chain. Proc Natl phism at position 86 of the HLA SA 1995 ; 92: 6567-71.

24 Ibbotson JP, Lowes JR. Potential role of superantigen induced activation of cell mediated immune mechanisms in the pathogenesis of Crohn's disease. Gut 1995; 36: $1-4$. 